\title{
USOS SOCIAIS DA ESCRITA EM ESPAÇO ESCOLAR: AS RELAÇÕES ESTABELECIDAS POR MULHERES INSERIDAS EM TURMA DE PRIMEIRO SEGMENTO DA EJA*
}

\author{
THE SOCIAL USES OF WRITTEN LANGUAGE IN THE SCHOOL SPACE OF ADULT WOMEN IN PROCESS \\ OF ALPHABETIZATION INSERTED IN A GRAPHOCENTRIC SOCIETY
USOS SOCIALES DE LA ESCRITURA EN ESPACIO ESCOLAR: LAS RELACIONES ESTABLECIDAS POR MUJERES INSERIDAS EN GRUPO DE PRIMER SEGMENTO DE EJA

\author{
Rosângela Pedralli ${ }^{1}$ \\ Universidade Federal de Santa Catarina - UFSC, Florianópolis, BR
}

\begin{abstract}
RESUMO: Este artigo, fruto de um estudo de caso do tipo etnográfico, tem como objeto a modalidade escrita da língua no cotidiano escolar de mulheres participantes do Curso de Educação de Jovens e Adultos - I Segmento da Prefeitura Municipal de Florianópolis. A questão que norteia o estudo é Como se caracterizam os usos sociais da escrita no espaço escolar das alfabetizandas adultas inseridas em uma sociedade grafocêntrica?. Teoricamente, este trabalho é embasado em estudos de Street (2003 e 1984), Hamilton (2000), Kleiman (2007, 2001 e 2001 [1995]), dentre outros. Os resultados sinalizam para usos escolares da escrita com uma dimensão ainda bastante artificializada, restrita ao ambiente escolar, com componentes de infantilização ou com aproximações com o senso comum, rarefazendo a escrita, ainda que haja um movimento em busca de novas configurações/aproximações com o ideário teórico dos gêneros discursivos (BAKHTIN, 2003 [1952/53]) e um trabalho ainda inicial com as novas tecnologias.

PALAVRAS-CHAVE: educação de Jovens e Adultos; alfabetização; letramento.
\end{abstract}

ABSTRACT: This article, result of a case study of ethnographic type, has as object the written modality of language in the scholar space of women participants of the Young and Adults Education Course -1st Segment of Florianópolis City Hall. The question that guides the study is "how are characterized the social uses of written language in the school space of adult women in process of alphabetization inserted in a graphocentric society?" Theoretically, this study is based on Street (2003 e 1984), Hamilton (2000), Kleiman (2007, 2001 e 2001 [1995]), Halté (2008 [1998]), among others. The results signalizes to school uses of written language with a dimension that is still a lot artificialized, restricted to the school space, with infantilization components or with approximations with common sense, rarefying the written language, yet having a movement in search for new configurations/approximations with the theoretical ideal of speech genres (BAKHTIN, 2003 [1952/53]) and a work still initial with the new technologies.

KEYWORDS: young and adults education; alphabetization; literacy.

RESUMEN: Este artículo, que resulta de un estudio de caso de tipo etnográfico, tiene como objeto la modalidad escrita de la lengua en el cotidiano escolar de mujeres que forman parte del Curso de Educación de Jóvenes y Adultos-I, segmento del Ayuntamiento de Florianópolis. El punto central de ese estudio es “ ¿Cómo se caracterizan los usos sociales de la escritura en el espacio escolar de las alfabetizandas adultas insertadas en una sociedad grafocéntrica? Teóricamente, este trabajo toma por base los estudios de Street (2003, 1984), Hamilton (2000), Kleiman (2007, 2001, 2001 [1995]), entre otros. Los resultados señalan para usos escolares de la escrita con una dimensión todavía muy artificial, restricta al ambiente escolar, con aspectos de infantilidad o con acercamientos al sentido común, lo que hace de la escrita algo menos denso, no obstante se observe un movimiento hacia nuevas configuraciones/acercamientos basado en el ideal teórico de los géneros discursivos (BAKHTIN, 2003 [1952/53]), así como un trabajo inicial con las nuevas tecnologías.

PALABRAS-CLAVE: educación de jóvenes y adultos; alfabetización; letramento.

\section{INTRODUÇÃO}

O presente artigo tem como objeto a modalidade escrita da língua no cotidiano escolar de mulheres, moradoras de Florianópolis - SC, inseridas no mercado de trabalho e participantes do Curso de Educação de Jovens e Adultos - I Segmento da Prefeitura Municipal de Florianópolis. O estudo se deu com a participação de três alfabetizandas 2 adultas, com idade entre 43 e 52 anos, integradas nesse programa, na

\footnotetext{
* Este trabalho consiste em um recorte de dissertação de mestrado intitulada "Usos sociais da escrita empreendidos por adultos alfabetizandos em programa educacional institucionalizado: dimensões ex traescolar e escolar" - 2011.

${ }^{1}$ Email: rosangelapedralli@hotmail.com.

2 Como ficará evidente à frente, pelo conjunto de dados analisados, as participantes do estudo são assim denominadas pelo seu enquadramento formal na instituição; no entanto, as três mulheres já apresentam proficiência nos usos da escrita, mesmo que em níveis diferentes.
} 
respectiva classe de alfabetização de Jovens e Adultos e que serão identificadas, ao longo do artigo, como E., M. e MG.3. O campo de pesquisa foi, então, uma escola da rede municipal do norte da ilha desse município.

Ao longo do processo de inserção nesse espaço, descrito a seguir, houve, na turma de alfabetização, troca das professoras-alfabetizadoras. Assim, nossa vivência na escola contou com dois momentos distintos quanto à docência: regência da alfabetizadora I e da alfabetizadora II - que serão assim identificadas ao longo do percurso analítico.

Metodologicamente, esse estudo é fruto de uma vivência de quase cinco meses no espaço escolar em que se deu a pesquisa, mais pontualmente, é claro, no que respeita à interação com as três participantes do estudo. Essa vivência acabou por gerar um conjunto de dados composto principalmente por notas de campo constituídas de anotações manuais (OLABUÉNAGA; ISPIZUA, 1989) -, entrevistas semiestruturadas gravadas em áudio (MARCONI; LAKATOS, 2007) - e imagens fotográficas.

Em se tratando especificamente das entrevistas semiestruturadas, interessa mencionar que as falas foram transcritas integralmente, com ajustes de forma limitados ao critério de não exposição da face das participantes de pesquisa no que respeita aos traços variacionistas, comumente objeto de preconceito linguístico. Importa, nesse sentido, o registro de que não obedecemos a técnicas da Análise da Conversa, visto que o foco da discussão empreendida no percurso analítico não envolvia questões de acento e sobreposição de turnos e conceitos afins.

O critério para o recorte dos excertos, tanto das entrevistas quanto das notas de campo, foi o eixo sobre o qual se construiu a questão de pesquisa que norteia este estudo - registrada no parágrafo que segue. Importa referir, ainda, que o processo de análise de conteúdo a que submetemos tais excertos se deu com base em teorizações de Hamilton (2000) sobre eventos de letramento, que contemplam as categorias de participantes, artefatos, contextos e ambientes.

Quanto aos usos sociais que essas mulheres em processo de alfabetização empreendem, considerando o contexto grafocêntrico em que estão inseridas, é nosso objetivo, nesta reflexão, responder à seguinte questão: Como se caracterizam os usos sociais da escrita no espaço escolar das alfabetizandas adultas, participantes desta pesquisa, inseridas nos contornos grafocêntricos das vivências sociais em Florianópolis - SC?

Os usos da escrita empreendidos pelas senhoras participantes desta pesquisa no contexto escolar tendem, como sustentaremos ao longo da discussão aqui proposta, a ter configurações tipicamente escolares, com as implicações da artificialidade - e não do artificialismo constitutivo (HALTÉ, 2008 [1998]) - que não raro caracteriza os fazeres didático-pedagógicos na tradição escolar, ou seja, não vimos solidificada ainda, nesse espaço, uma ação pedagógica que viabilize o alargamento desses usos no que diz respeito ao contexto extraescolar, tal qual registram teorizações contemporâneas com foco nas práticas sociais.

Tais usos tipicamente escolares sugerem uma ação escolar ainda pouco atenta à necessidade de reconhecer as práticas de letramento (STREET, 1988; HAMILTON, 2000) que caracterizam os alunos, a fim de ressignificá-las, no processo de hibridização entre letramentos dominantes e letramentos vernaculares ao qual nos convida Street (2003), tanto quanto, em outra perspectiva teórica, nos exorta o ideário freiriano.

Essa ação tipicamente escolarizada tem um componente adicional: descaracteriza-se em relação às abordagens que focalizam gêneros discursivos (BAKHTIN, 2003 [1952/53]) e que, ao focalizá-los, aproximam os eventos de letramento (HEATH, 2001 [1982]; HAMILTON, 2000) que têm lugar na escola dos eventos de letramento que têm lugar fora dela. Logo, as ações pedagógicas nesse contexto nos

\footnotetext{
3 Estamos conscientes de que, em pesquisas com geração de dados a partir de instrumentos de tipo etnográfico, os participantes tendem a ser referenciados por nomes fictícios. Optamos, porém, por referenciar tais participantes pela inicial de seus próprios nomes, grafada em itálico e seguida de ponto para evitar ambiguidades com o uso de letras maiúsculas.
} 
remetem, sob vários aspectos e ainda que não intencionalmente, ao modelo autônomo de letramento (STREET, 1984), que discutiremos à frente.

Tendo em vista, assim, nossa proposta de reflexão, este estudo conta com quatro seções de conteúdo, além das considerações finais: (1) As inserções nas ações de escrita escolarizada empreendidas por E., M. e MG.; (2) Implicações identitárias do processo educativo: as representações acerca do uso da escrita nesse espaço escolar; (3) Usos da escrita no espaço escolar: usos escolares; (4) O movimento de ressignificação das práticas escolarizadas: os gêneros discursivos e o trabalho com as novas tecnologias. Cabe mencionar que, como seções de conteúdo que são, fizemos a opção por não trazer uma seção com o aporte teórico separadamente. Nelas, os dados, o processo analítico e os conceitos teóricos à luz dos quais se deu esse processo são apresentados entrelaçadamente. Isso, ao nosso ver, torna a leitura menos exaustiva.

Eis que se seguem, então, as seções.

\section{AS INSERÇÕES NAS AÇÕES DE ESCRITA ESCOLARIZADA EMPREENDIDAS POR $E$., $M$., $M G$}

O modelo autônomo de letramento, segundo Street (1984), é caracterizado pela (tentativa de) dissociação das dimensões social e política nas práticas de leitura e de escrita. Essa dissociação entre a escrita, a leitura e os aspectos sociopolíticos solidifica falsas concepções, como a pseudoneutralidade do ensino, o entendimento de leitura e de escrita como sistemas independentes e fechados em si mesmos e a supervalorização da escola no processo de 'aquisição' de 'altos níveis de letramento'. Isso significa dizer, em alguma medida, que tal modelo tende a reproduzir a cultura de grupos dominantes.

Sob essa perspectiva, o modelo autônomo contribui para a propagação do ideário de que há uma única forma de letramento a ser desenvolvida, ou seja, que os sujeitos, quer sejam crianças ou adultos, construiriam seu processo de aprendizagem de leitura e escrita da mesma forma em todos os contextos. Para Kleiman (2001 [1995], p. 22), “[...] a característica de 'autonomia' refere-se ao fato de que a escrita seria, nesse modelo, um artefato completo em si mesmo, com consistência interna” ou, por outra, independentemente dos letramentos locais, a aprendizagem se daria segundo um mesmo modelo, caminho, processo.

Street (1984; 2003) afirma que letramento, tomado à luz do modelo autônomo, é concebido como uma habilidade técnica, ou seja, “[...] as pessoas precisam aprender uma forma de decodificar as letras, e depois poderão fazer o que desejarem com o recém-adquirido letramento” (STREET, 2003, p. 4). Dessa forma, o modelo autônomo se erige a partir da compreensão de que, em si mesmo, o letramento trará efeitos sobre outras práticas sociais e cognitivas e, ainda, tende a apregoar neutralidade e universalidade que seriam constitutivas do processo de 'aquisição' do letramento (STREET, 2003), no entanto, “[ [...] the 'autonomous' model is $[\ldots]$ constructed for a specific political purpose" 4 (STREET, 1984, p. 19).

A sensibilidade às vivências dos alunos, por outro lado, é tema fulcral na obra freiriana. Para o autor, a leitura da palavra, da frase, da sentença, não pode significar uma ruptura com a "leitura" do mundo. A leitura da palavra, sim, deve ser a leitura da 'palavramundo'. No pensamento de Freire (2009 [1982]), o movimento do mundo à palavra e da palavra ao mundo está sempre presente no processo. Tal dinâmica é, para o autor, central no processo de alfabetização. O autor defende, assim, que, ao empreender processos educativos, é necessário considerar a realidade social tanto dos sujeitos como dos contextos em que essas ações serão desenvolvidas.

Os estudos do letramento, segundo Vóvio (2010), associam ao ideário de Freire a focalização do local. À luz dessa compreensão, registramos a seguir uma nota de campo que, ao nosso ver, é ilustrativa da importância de considerar as vivências dos alunos nos processos de escolarização.

4. O modelo ‘autônomo’ é [...] construído para um propósito político específico. 
(1) Quando a nova professora chega à sala de aula, faz breve autoapresentação e, em seguida, pede aos alunos que também o façam explicando por que estão na EJA. Na fala de M. se sobressai a seguinte afirmação: “[...] já estive na escola antes, estudei até a quinta série, mas já faz quarenta anos. Só que eu leio, estou sempre lendo, eu leio tudo”. (Diário de Campo - 09 de junho de 2011. Nota no 1).

M. informa, durante todo o tempo que estivemos na escola, ser leitora; entrega Horas de Produções Externas - HPEs 5 - com resumo de leituras, uma prática que talvez merecesse um olhar mais cuidadoso na elaboração docente de atividades em sala de aula, porque constitui, no caso de M., um evento de letramento extraescolar vinculado à erudição que parece não ter espaço efetivo nessa esfera escolar, a qual tende a lidar com representações apriorísticas e universalizantes sobre os alunos que recebe: possivelmente as experiências de M. com a leitura não convirjam com essas representações e, nessa condição, sejam invisibilizadas naquele espaço.

Considerando ainda a nota (1), num dos últimos momentos de nossas vivências na escola, ao conversarmos - M., o coordenador pedagógico e eu - durante o intervalo, o coordenador mencionou a minha visita à casa dessa aluna. Nessa ocasião, contamos a ele, M. e eu, sobre o acervo com que conta a aluna em sua residência e sobre seu hábito de leitura literária. O coordenador ficou visivelmente surpreso, revelando desconhecer essas particularidades de M., reiterando nossa inferenciação acerca do que entendemos ser uma invisibilidade de vivências discentes destoantes do padrão aprioristicamente construído no espaço escolar.

Contrariamente a essa invisibilidade, parece muito presente tanto nos documentos parametrizadores, quanto no cotidiano dessa instituição escolar, uma preocupação relacionada com a questão da evasão. Observa-se na Resolução $n^{\circ}$ 02/2010, que visa estabelecer as normas operacionais que instituem as Diretrizes Gerais e Operacionais para a Educação de Jovens e Adultos, uma preocupação bastante substancial com a realidade microcultural dos alunos expressa já no artigo $1^{\circ}$ desse documento, ao asseverar que constitui atribuição da EJA no município “[...] assegurar, gratuitamente, oportunidades educacionais apropriadas, consideradas as características dos estudantes, seus interesses, suas condições de vida e de trabalho [...]” (SME, 2005, p. 1).

Essa preocupação, asseverada pelo documento, se materializa na escola pela relação bastante próxima que gestão escolar, professores e alunos têm nos momentos de convivência no espaço escolar. Professores, alunos e coordenador pedagógico lancham juntos, praticam atividades juntos, como jogos de futebol, pingpong e afins. É bastante significativa a preocupação por parte da coordenação, bem como dos professores, com o absenteísmo dos alunos. Por vezes, durante o inverno chuvoso, que tende a dificultar muito a locomoção dos alunos, presenciei6 diálogos como esses - fala do coordenador pedagógico a um grupo de alunos: (2) Quando for assim [semana fria e chuvosa], vocês me liguem que eu busco vocês. Não deixem de vir à aula, me liguem (Diário de Campo - 19 de maio de 2011. Nota no 2). Nessa preocupação, que está relacionada a um escopo maior de gestão, vemos que a atenção às vivências dos alunos está estreitamente relacionada à questão da evasão; entretanto essa preocupação parece não se refletir em ações pedagógicas que enfoquem a realidade microcultural desses alfabetizandos quanto à utilização da escrita em suas vivências e em sua historicidade.

Assim, do mesmo modo que os eventos de letramento do qual participam os alunos parecem ser os tipicamente escolares, a interação em sala de aula, de modo mais geral, também parece ter contornos tipicamente escolares ou configuração tão alargada que prescinde a existência do próprio material escrito. A interação a seguir descrita, materializada em notas de campo, sugere insularização das interações ao espaço

\footnotetext{
${ }^{5}$ As horas não presenciais ou horas de produção externa (HPE) são registradas a partir da participação em atividades sociais, culturais e esportivas na comunidade (mutirões, coral, grupos de dança, teatro, música); leitura de livros, jornais e revistas; síntese de filmes assistidos ou programas de televisão; idas a cinema e/ou ao teatro; participação em associações comunitárias; ida a cursos e palestras diversos; realização de atividades propostas pelos professores (atividades de casa, pesquisas na comunidade, entrevistas); passeios, saídas programadas a museus, parques etc. Essas HPEs são registradas no caderno de estudante do aluno e em planilha própria que é distribuída a todos os professores.

${ }^{6}$ Alternaremos, ao longo do artigo, os usos de primeira pessoa do singular e de primeira pessoa do plural, dada a necessidade de, em muitas situações, eu me assumir como enunciadora.
} 
escolar. As perguntas feitas pela aluna refletem o discurso prototípico da escola, isto é, preocupação acentuada com ortografia, pontuação etc..

(3) Oficina sobre origem da vida ministrada por professor do Segmento II: alunos escrevem ou desenham sobre suas hipóteses acerca da origem da vida após explicação do professor. A aluna M. pergunta: "Essência é com dois S?" Professor responde que sim. "E tem chapeuzinho no e?" - a aluna torna a perguntar, ao que o professor responde que sim. (Diário de Campo - 04 de julho de 2011 . Nota no 3).

(4) Oficina sobre origem da vida ministrada por professor do II Segmento: enquanto uma das alunas (MG.) se empenha em copiar os termos mais desconhecidos que emergem da explicação do professor, como autótrofos e heterótrofos, biogênese e abiogênese, os outros colegas não realizam nenhum registro. Uma das colegas (E.) é interpelada pela outra (MG.) pelo fato de não estar copiando, a isso E. responde: "Eu não vou copiar porque não consigo escrever esses nomes e não entendo nada. Estou esperando o professor dizer para eu entender". (Diário de Campo - 04 de julho de 2011. Nota no 4).

Ainda quanto às interações em sala de aula e aos usos sociais da escrita empreendidos na dimensão escolar, na nota de campo no 4, parecem-nos claros dois movimentos: a compreensão por parte de MG. de uma das funções da escrita, a escrita como recurso de memória. Dessa forma, ela anota termos de cuja nomenclatura certamente não se lembrará depois. Além disso, MG. parece estar no caminho de entender as práticas valorizadas na esfera escolar, fazer registros escritos das aulas, por exemplo.

O outro movimento perceptível na interação registrada nessa mesma nota (4) é a dependência por parte de E. em relação à oralidade para construção de sentidos e, por implicação, de conhecimento. Para E., não parece estar ainda muito claro o papel da escrita como recurso de memória e seu espaço valorizado na esfera escolar. As posições divergentes das duas alunas diante da situação são elucidativas dos momentos distintos vivenciados por elas no processo de aculturação compreendido no processo de alfabetização em si (KLEIMAN, 2001), o que nos remete a uma discussão que, em nosso entendimento, é nodal em se tratando da reflexão neste estudo: os processos identitários implicados na aprendizagem da modalidade escrita da língua.

\section{IMPLICAÇÕES IDENTITÁRIAS DO PROCESSO EDUCATIVO: AS REPRESENTAÇÕES ACERCA DO USO DA ESCRITA NESSE ESPAÇO ESCOLAR}

Kleiman (2001) defende que, na aprendizagem da modalidade escrita da língua, está implicado um processo de aculturação que se dá por meio e na direção das práticas discursivas de grupos escolarizados. Desse modo, não se trata apenas de um processo marcado pelo conflito, inerente a todo percurso de aprendizagem, mas também um processo de perda e luta social. Semelhantemente a esse processo de aculturação, Souza e Mota (2007) afirmam que o alfabetizando sofre, ao ser inserido na esfera escolar, um rito de passagem. Esse rito teria, assim, uma configuração de passagem da tradição oral, microculturalmente construída, ao espaço grafocêntrico, macroculturalmente constituído, o que gera, com a inserção ativa no mundo letrado, um novo patamar de identidade, segundo as autoras.

Escritos de Vóvio (2010) corroboram essas concepções ao registrarem que mudanças nas práticas dos alfabetizandos resultam em mudanças identitárias. O processo de mudança identitária é, por sua vez, uma questão de saber e poder (SILVA, 2011). O processo de escolarização, para Silva (2011), conta com uma tríade inseparável: conhecimento, identidade e poder7. Para Kleiman (2001), essa dimensão de poder, relacionada com o processo de escolarização, está diretamente ligada ao processo de aculturação, na medida em que a aprendizagem da leitura e da escrita não é equiparada à aprendizagem de uma técnica ou de um conjunto de conhecimentos. As práticas 8 letradas de que se constitui o processo de alfabetização e de

\footnotetext{
${ }^{7}$ Importa registrarmos que, embora o autor tenha filiação epistemológica distinta da nossa, nesse ponto, nossa compreensão sobre essa questão, especificamente, converge com a dele.

${ }^{8}$ Usamos, aqui, o termo práticas no sentido de usos cotidianos. Quando nos referirmos a práticas de letramento, o faremos em itálico, tomando o conceito tal qual o definem Street (1988) e Hamilton (2000).
} 
escolarização de maneira mais ampla estão fundamentalmente ligadas às estruturas sociais, complexos sistemas culturais, tomadas dentro de estruturas de poder.

O uso da escrita na esfera escolar, no espaço social em que se desenvolveu este estudo, não parece naturalizado entre os alunos em razão de um amplo conjunto de questões que constituem esse processo. Embora grande parte dos alunos da turma já tivesse algum domínio da escrita por ocasião do retorno à escola, esse domínio estava ainda em um processo bem inicial e conflitivo de compreensão e apropriação do conjunto de práticas tipicamente escolares, como fazer perguntas, realizar anotações etc., assim como depreendemos na nota de campo a seguir: (5) Durante a oficina sobre origem da vida, os alunos parecem interessados na aula, no entanto, não fazem registros e/ou perguntas (Diário de Campo - 04 de julho de 2011. Nota no 5).

Aprender a ler e escrever, assim, em muitos espaços de EJA, constitui um processo de aculturação conflitivo, visto que acarreta perda e substituição de práticas discursivas orais que até então serviam ao aluno (KLEIMAN, 2001). Isso se dá, em alguma medida, também, pelo processo de construção da própria identidade de estudantes pelo qual passam esses alunos, de modo que esse lugar de estudante não é ainda bem compreendido.

A importância da construção dessa identidade institucional do aluno é asseverada por Kleiman (2001), ancorada no pensamento de Bourdieu (1993). Tal identidade institucional do aluno é definida pela autora como sendo um processo de investidura, como atribuição de papéis, cargos etc.. A autora (2001) defende que a própria permanência do aluno em cursos de alfabetização institucionalizados depende, entre outros fatores, da construção de identidade institucional do aluno. A escola é responsável, dessa forma, pela constituição do sujeito, aos olhos dos outros, com a identidade de aluno, transformando "[...] a representação do sujeito assim legitimado ou investido" (KLEIMAN, 2001, p. 274). Essa responsabilidade da escola na construção identitária do aluno não garante, entretanto, que suas normas venham a figurar no âmago de cada sujeito, do mesmo modo que nada pode garantir que as identidades atribuídas sejam efetivamente as identidades experienciadas (GERALDI, 2010).

Nos excertos a seguir, registramos falas muito expressivas de questões de construção e compartilhamento identitários envolvidas diretamente nesse processo de continuidade/evasão desses alunos de EJA.

(6) Esses alunos [quatro no total] já estavam no segundo segmento, mas precisaram voltar. Já tinham feito pesquisas e tudo, mas tivemos que colocá-los de volta na turma de primeiro segmento. Para nós isso é um problema porque eles pensam que estão regredindo. Nós tentamos explicar que [tal situação de retorno] é para que eles tenham mais atenção à escrita e à leitura, mas às vezes eles não entendem. Só o L. [aluno que não integra diretamente o grupo de participantes dessa pesquisa] que voltou porque não se deu bem na outra turma. Quando os três [colegas do ano anterior] voltaram para a alfabetização, ele ficou sozinho lá, não se enturmou, não vinha mais quase para a escola, então achamos melhor ele estar aqui no primeiro segmento. (Diário de Campo - 10 de maio de 2011. Nota no 06).

(7) Eu não gostava [da turma de segundo segmento], era chata. Legal mesmo era a turma do ano passado, né E.? [interpela colega que voltou com ele para o primeiro segmento, por razões diferentes] A gente ria um monte, conversava, brincava, era bem legal... Agora que eles botaram nós nessa, tá bom também. (Diário de Campo - 10 de maio de 2011. Nota no 07).

O primeiro dos registros é o resgate de uma fala do coordenador pedagógico da escola sobre o retorno de alguns alunos à classe de primeiro segmento; já o segundo excerto é o registro da fala do aluno mencionado no relato do coordenador, que remete à importância da construção de uma identidade de turma para a permanência na escola.

\section{USOS DA ESCRITA NO ESPAÇO ESCOLAR: USOS ESCOLARES}

À luz de outro enfoque, ou seja, com relação ao tratamento dado à escrita nas ações didáticas de que tomam parte essas três participantes de pesquisa, observamos, em determinados momentos, uma configuração tão 
alargada das interações - no sentido de estabelecer uma interface tão estreita com o senso comum que perde o foco nos artefatos escritos (HAMILTON, 2000) - em sala de aula que prescinde da existência do próprio material escrito. A nota de campo a seguir parece ilustrar bem esse tipo de situação.

(8) A professora fixa cartolina com a cantiga de ninar "Boi da cara preta" na lousa [ver a seguir], lê a letra com os alunos e pergunta "Quem lembra dessa musiquinha?”. Os alunos começam a relatar passagens em que já ouviram essa música. Os alunos mais jovens dão indícios claros de que esses relatos não interessam a eles. Um deles se levanta e vai olhar o mapa que está preso à parede, enquanto outro mexe no celular. A professora os chama, dizendo que eles devem participar da discussão. Os demais alunos continuam a relatar episódios em que contaram a cantiga aos filhos ou que ouviram-na. Os alunos mais velhos começam a relatar situações vivenciadas por eles quando crianças, as diferenças em relação a hoje em dia. O texto é secundarizado. Ao final da aula, a professora afirma que retomará o texto na próxima aula. (Diário de Campo - 13 de maio de 2011. Nota no 08).

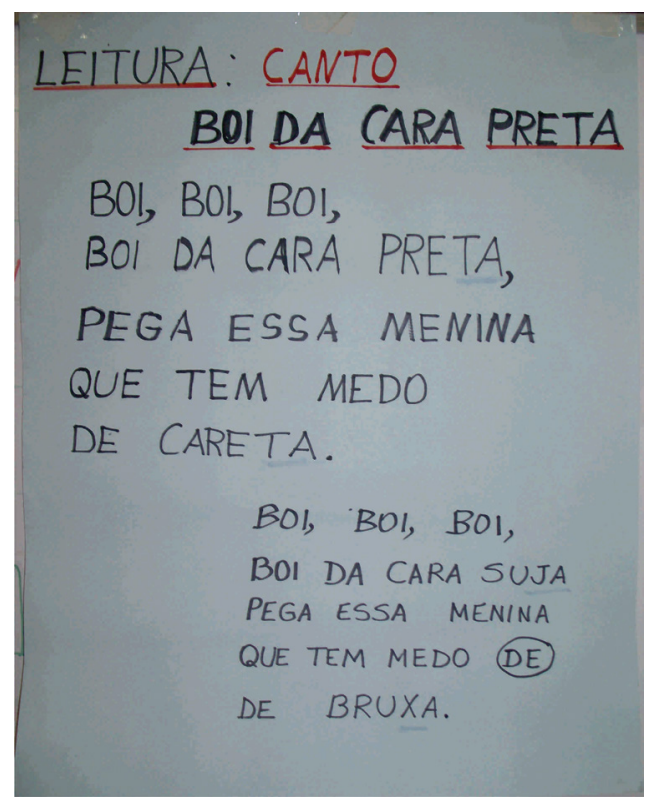

Imagem 1: Texto em cartolina trabalhado em sala de aula - professora I.

Fonte: Geração de dados da autora.

Importa mencionar que a professora me informa antes do início da aula que trabalhará um texto usado à tarde com a turma de alfabetização de crianças. Ela conta que a aula foi muito bem sucedida e que "[....] os pequenos adoraram”. Parece haver, nessa situação específica, uma ação pedagógica infantilizada e, sob vários aspectos, incompatível com a clientela adulta. Afora essa questão, a abordagem da professora secundariza o conteúdo do texto em favor de discussões de senso comum, perdendo de vista, a nosso ver, o foco da ação pedagógica em questão: a apropriação/potencialização das práticas de leitura e escrita por parte dos alunos. Assim, o fazer docente assume contornos tão alargados que prescinde da existência do próprio material escrito em sala.

Ainda com relação às notas no 3, 4 e 5 , estas suscitam reflexões acerca do processo conflitivo pelo qual passam esses alunos frente ao uso da escrita - aspecto abordado na segunda seção. Essa relação conflitiva, embora seja constitutiva do processo de alfabetização (KLEIMAN, 2001; SOUZA; MOTA, 2007; VÓVIO, 2010), parece potencializada pela exposição escassa desses sujeitos a eventos de letramento que lhes facultem a compreensão de funções diferentes para a escrita na sociedade, como vemos materializado na nota de campo no 8. Uma ação que vise à compreensão de funções sociais outras - para além daquelas já dominadas - que a escrita possa ter a partir do trabalho com eventos de letramento diversos, não deve pretender a substituição das práticas discursivas orais que até então serviam ao aluno (KLEIMAN, 2001), tanto quanto não pode circunscrever-se a evocá-las. Não entendemos ser o mote do processo de alfabetização limitar-se a facultar ao aluno novas formas de fazer o que ele já fez durante anos, em seu 
trânsito social, independentemente da escrita, mas lhe facultar a apropriação/implementação das práticas de leitura e escrita sem as quais determinadas atividades seriam limitadas.

Ações pedagógicas pautadas no trabalho com eventos de letramento que transcendam aqueles tipicamente escolares são defendidas pelo modelo ideológico de letramento. À luz desse modelo, segundo Street (1984), escrita e leitura são vinculadas às práticas sociais. Assim, em se tratando dos materiais escritos, importam não apenas o conteúdo e a situação de comunicação na qual são produzidos, mas valores, ideologias e representações. Para Baltar (2010, p. 216), o modelo de letramento ideológico considera " [...] o processo histórico, conflituoso, as relações sociopolíticas de poder na sociedade para a distribuição dos bens culturais e econômicos". Sob essa concepção, as práticas de letramento ocorrem no bojo da estrutura social, interpeladas pelas ideologias (BALTAR, 2010). Nessa compreensão, as práticas de letramento são analisadas pela ótica da hegemonia cultural, do poder, das relações sociais. Para este último autor, a relevância do modelo ideológico está nas contribuições possíveis, especialmente em se tratando das agências de letramento de prestígio, como a escola e a universidade, em favor da transformação da aparente neutralidade atribuída aos discursos dessas instituições em "[...] uma visão que contemple a distribuição de poder na sociedade” (BALTAR, 2010, p. 216). Nesse modelo, são considerados, portanto, aspectos culturais e estruturas de poder que perpassam as práticas de letramento, podendo ser tanto instrumentos de dominação como instrumentos de construção da cidadania, dependendo dos interesses que ancoram o processo. Entendemos que, em boa medida, quando as práticas escolares não desafiam os sujeitos a transcender os conhecimentos já consolidados (VIGOTSKI, 2000 [1978]), não contribuem para essa visão mais ampla dos eventos de letramento (STREET, 1984).

Para Street (2003), a concepção ideológica de letramento faculta uma visão mais sensível culturalmente às práticas de letramento, considerando que são bastante distintas de um contexto para outro. $\mathrm{O}$ modelo ideológico assume premissas diferentes das adotadas pelo modelo autônomo e propõe que o letramento seja concebido como uma prática de cunho social, portanto situado sócio-historicamente. Além disso, esse modelo nega a neutralidade conferida ao processo pelo modelo autônomo e compreende o letramento como “[...] sempre envolto em princípios epistemológicos socialmente construídos" (STREET, 2003, p. 4). Assim sendo, é possível afirmar que "[...] práticas variáveis de letramento são sempre enraizadas em relações de poder, e que as aparentes inocência e neutralidade das 'regras' atuam para disfarçar as maneiras de manter esse poder através do letramento [...]” (STREET, 2003, p. 10). As vivências neste estudo chamaram nossa atenção para formas como - não raro sem o saber efetivamente - endossamos relações sociais assimétricas: quando, por exemplo, nossa ação se limita a focalizar o senso comum - tal qual se deu na cantiga infantil -, sem expandir representações de mundo de nossos alunos.

Outro aspecto que chamou nossa atenção foi a circunscrição das produções textuais a HPEs. Isso porque, o suporte HPE não se presta para a instituição de relações sociais efetivas, ainda que, nessa atividade, haja uma forte relação com as vivências dos alunos e com os usos da escrita que eles empreendem fora da escola. Vale, pois, a despeito disso, o alerta de Kleiman (2001 [1995], p. 45): “[...] uma prática escolar que visa ao domínio da escrita para a produção de um texto expositivo abstrato, internamente consistente, pressupõe uma separação polarizada entre a oralidade e a escrita”. Assim, ainda que as HPEs estejam ancoradas em vivências dos alfabetizandos, corporificam, em sua materialização no suporte, a artificialidade escolar. Parece haver, nesse processo, um movimento em busca de maiores elos entre ambientação escolar e ambientação extraescolar, movimento que ainda esbarra na tradição socialmente asséptica dos processos de escolarização.

A prevalência de produções textuais de HPEs nesse contexto escolar é evidenciada neste excerto de entrevistas: (9) "Eu faço bastante HPEs para escola; a maioria mesmo é resumo de livros. Não faço cópia, nunca entrego cópia para HPE” (M.; entrevista realizada em 07 de agosto de 2011). Tal prevalência pode ser explicada pelo caráter avaliativo dessas produções nesse contexto e pelo incentivo por parte dos professores para que os alunos transformem suas experiências culturais escolares e extraescolares em HPEs. Ainda excerto de entrevista que parece materializar a mencionada prevalência: (10) "No colégio, a 
gente escreve de tudo um pouco e principalmente que dê a nossa opinião, pra eles verem até aonde vai nosso conhecimento, lendo, escrevendo, apresentando, né?” (MG.; entrevista realizada em 12 de agosto de 2011).

Embora haja, como ilustra bem a fala de MG., um encorajamento por parte dos professores para que, nas produções textuais orais e escritas, os alunos expressem suas opiniões, quando do auxílio à professora na correção dessas produções, observamos grande número de HPEs resultantes de cópias de jornais, revistas; enfim, materiais com os quais os alunos tiveram contato na dimensão extraescolar; além de relatos de atividades realizadas em sala, como discussões, por exemplo. Esse encorajamento constitui um movimento dos docentes no sentido de ressignificar essa prática a fim de que os alunos escrevam a partir das leituras que realizam, dos filmes a que assistem, dos eventos culturais de que participam etc., enfocando as opiniões pessoais acerca desses eventos de letramento.

O encorajamento por parte do corpo docente às mudanças na escrita de HPEs ganha contornos bem nítidos ao observarmos a pontuação atribuída a cada tipo de produção com essa finalidade.

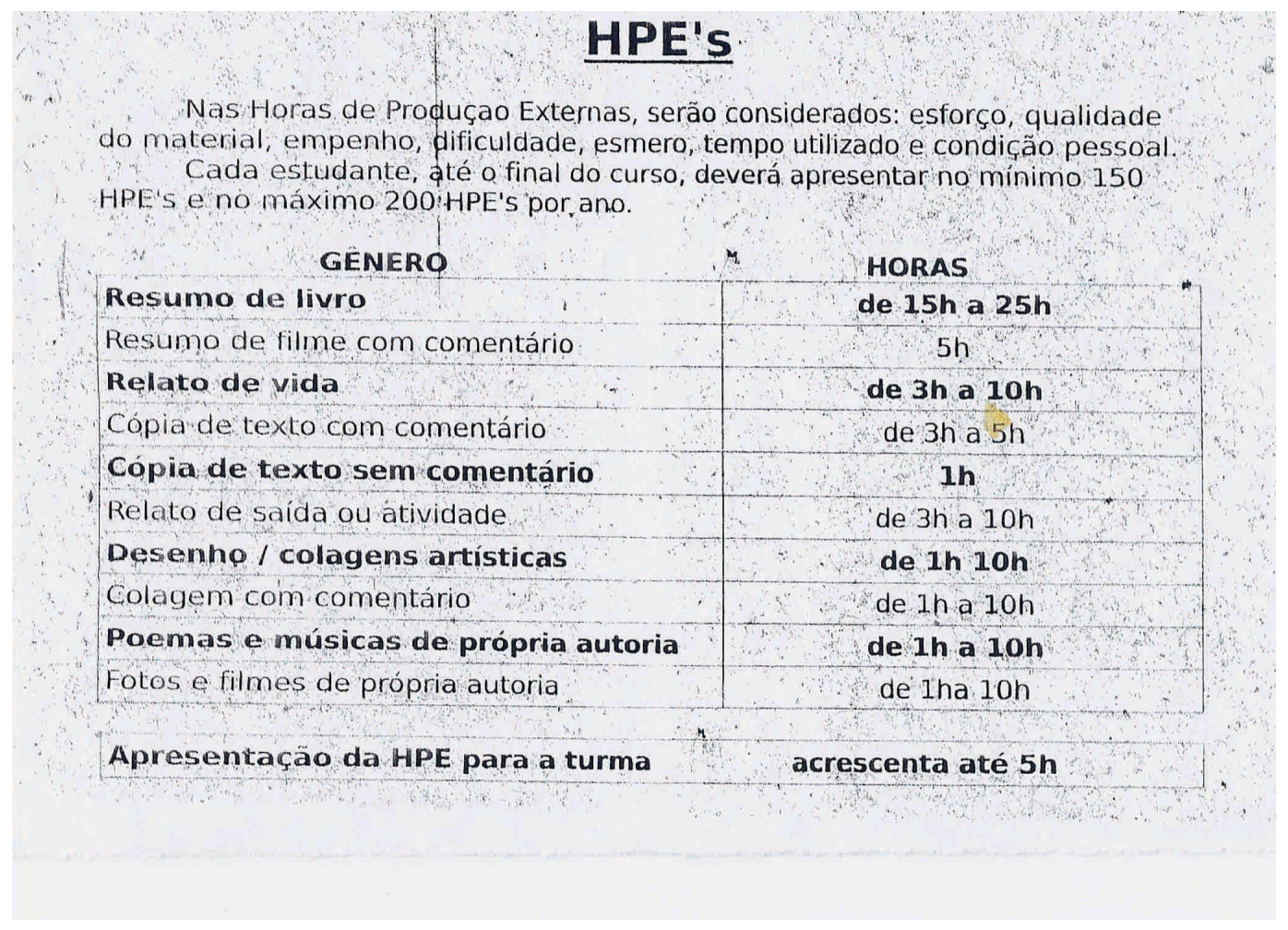

Imagem 2: Tabela de equivalência das Horas de Produção Externas. Fonte: Distribuição na escola aos docentes.

Esse movimento, no entanto, não parece resultar em ações educativas que reverberem no contexto extraescolar dos alunos. A própria metodologia adotada pelo programa de alfabetização de instituição do suporte HPE como portador de produções textuais de toda ordem não tende a favorecer essa tentativa de ressignificação empreendida pela escola. Nesse ponto, em que problematizamos a prevalência da produção textual endereçada ao suporte HPE nesse contexto, cabe refletir acerca dos artefatos e eventos de letramento prevalecentes nas proposições didáticas à turma. Assim, nos Gráficos 1 e 2 são apresentados, respectivamente, os artefatos e os eventos de letramento trabalhados em sala de aula durante o período de observações 9 .

\footnotetext{
9 Fizemos a opção por não focalizar tais artefatos e eventos pela perspectiva dos gêneros discursivos, porque esse ideário não constitui eixo efetivo do aporte teórico deste estudo.
} 


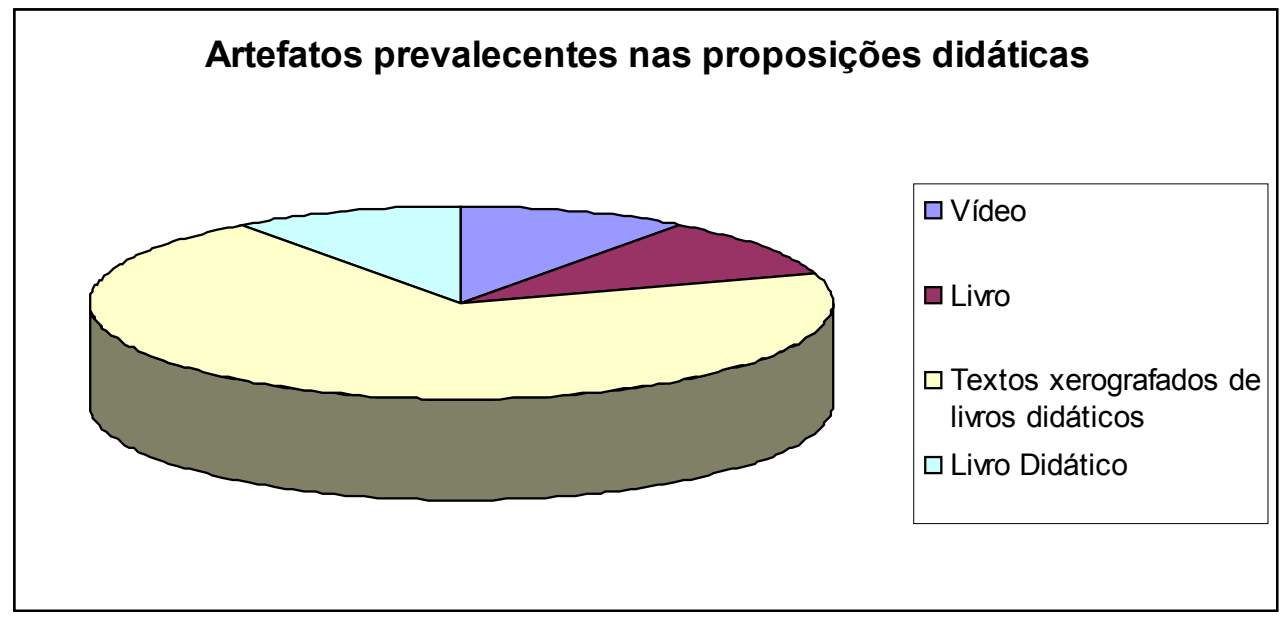

Gráfico 1: Artefatos prevalecentes nas proposições didáticas.

Fonte: Construção da autora.

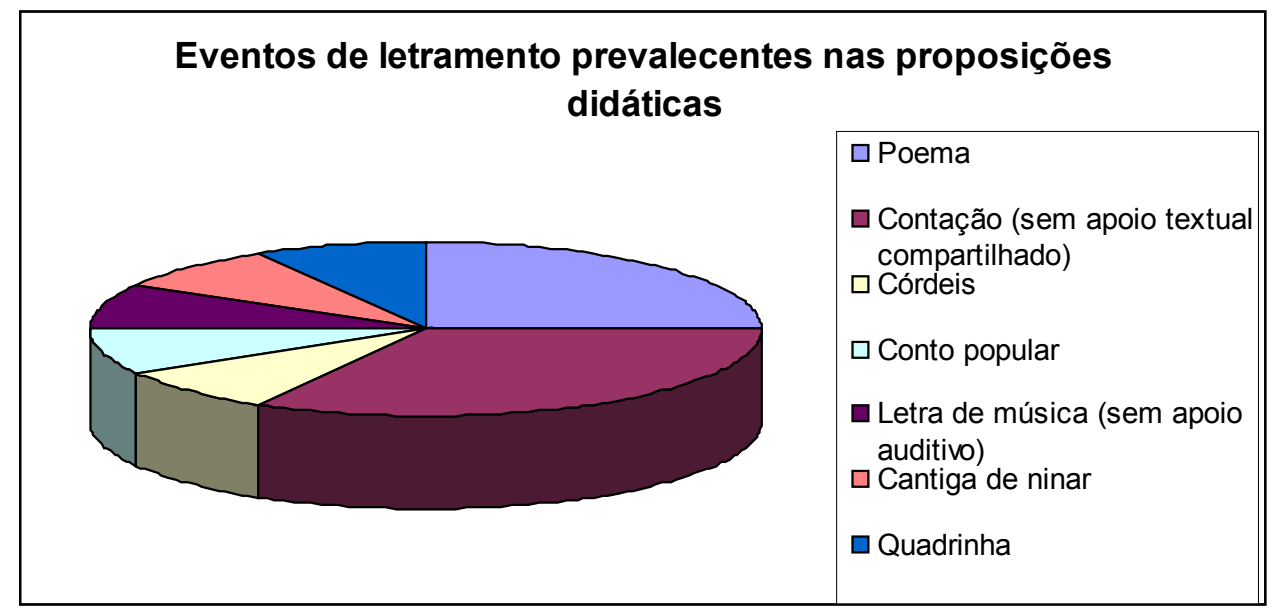

Gráfico 2: Eventos de letramento prevalecentes nas proposições didáticas.

Fonte: Construção da autora.

Observa-se, no Gráfico 1, uma ampla prevalência de textos xerografados de livros didáticos 10. Nessa prática de entrega do texto xerografado de material didático, os alunos acabam por se inserir em eventos de letramento em que as relações interpessoais são instituídas por meio de notícia de jornal, poema etc. No entanto, uma incoerência se revela nessa prática à luz do ideário ao qual nos filiamos, que entende ser necessário que o ensino do código se dê em contextos de sentido, por meio de práticas sociais de usos da língua (KLEIMAN, 2007). O trabalho com tais práticas sociais em sala de aula se justifica pela tentativa de manutenção do eixo interacional nas atividades com textos e se mostra um caminho para minimizar, em alguma medida, a artificialidade escolar, aproximando eventos de letramento propostos na escola a eventos de letramento que têm lugar no cotidiano da vida humana.

A incoerência, a nosso ver, consiste no fato de que, embora entendamos que, ao levarmos um texto materializado à sala de aula, independentemente do gênero discursivo (BAKHTIN, 2003 [1952/53]), ele sempre terá sido retirado da esfera da atividade humana em que institui relações interpessoais a priori, quando impresso em um livro didático, ele é afastado mais efetivamente dos usos da escrita tal qual eles têm

\footnotetext{
${ }^{10}$ Interessa registrar, nesse ponto, a impossibilidade de analisar os usos da escrita que fazem os sujeitos na esfera escolar sem que se analisem as concepções teóricas que movem a ação pedagógica que visa promover tais usos. Logo, embora sejam o enfoque da análise, neste momento, os usos empreendidos na esfera escolar, acabou por ser empreendida uma análise das concepções docentes subjacentes a essas escolhas.
} 
lugar no cotidiano, visto que é apresentado fora de seu suporte de circulação e o eixo interacional que o justificou é perdido. Além disso, no momento em que se opta por esse tipo de prática, perde-se uma oportunidade de inserir tais alunos em eventos de letramento efetivos e significativos, o que não aconteceria se não fosse a interferência da escola, visto que as interações instituídas pelos livros didáticos ficam circunscritas à esfera escolar.

Essa prática, a nosso ver, denota fragilidades teórica e pedagógica em se tratando da formação docente. Tais fragilidades têm contornos diferentes para cada uma das professoras participantes deste estudo. No caso da primeira professora (alfabetizadora I), há conhecimento em construção acerca da importância de trabalhar com gêneros discursivos materializados em textos com circulação social efetiva e que signifiquem para alunos. No caso da segunda alfabetizadora (alfabetizadora II), observamos o início de um movimento em favor do trabalho com os usos sociais da escrita na medida em que vemos uma preocupação em trazer textos que tenham relação com a realidade social dos alunos e com a instituição de relações sociais efetivas. Há, no entanto, circunscrições quanto à apropriação teórica, ainda em construção, e descontinuidades quando da elaboração didática (HALTÉ, 2008 [1998]), o que parece se eliciar na seguinte nota de campo:

(11) A professora traz uma notícia xerografada de material didático chamada "Sempre em maior número e à margem da vida”. O texto foi publicado em seu suporte original, o jornal, em 1995. A alfabetizadora procura encaminhar a leitura relacionando ao fato de ter havido uma semana muito fria e com notícias sobre mortes em função do frio, campanhas de doação de agasalhos, de alimentos, acerca das pessoas que moram na rua etc. Discute, à luz do texto, as causas que levam essas pessoas a estarem nas ruas, tais como vícios em drogas, álcool, pobreza, impossibilidade de pagar aluguel etc. Foram levantadas pelos alunos questões sobre a inoperância das políticas públicas no sentido de prover albergues, recursos para geração de empregos, priorização por parte dos governantes do custeio de festas como o Carnaval, por exemplo. Os alunos apontam como possíveis soluções a criação de empregos, albergues, promoção da saúde etc. A alfabetizadora pede, então, aos alunos que respondam à problemática que se elicia do texto: $\mathrm{O}$ que fazer para diminuir a quantidade de moradores de rua? O problema deve ser respondido por meio da escrita de um parágrafo. Os alunos o fazem. Além disso, a professora pede que cinco questões sejam respondidas. Há, por parte dos alunos, muita dificuldade em compreender as questões propostas que foram também xerografadas do mesmo material didático. (Diário de Campo - 07 de julho de 2011. Nota no 11$)$.

Observamos na ação pedagógica, registrada nessa nota de campo, uma compreensão por parte da professora acerca da sensibilidade ao conhecimento e às vivências dos alunos, assim como proposto pelo ideário freiriano e pelos estudos do letramento. Há a compreensão, também, no momento em que ela seleciona uma notícia, de que isso se dá via textos que se materializam em gêneros discursivos, os quais instituem relações sociais em diferentes esferas da atividade humana (BAKHTIN, 2003 [1952/53]), como proposto por Kleiman (2007). A concepção de gêneros do discurso remete à linguagem como mediadora/instituidora das relações sociais, ou seja, relacionamo-nos com o outro e com o mundo por meio da linguagem (BAKHTIN, $2003[1952 / 53])$.

Observamos, no entanto, que há uma questão que merece um olhar mais cuidado na abordagem docente e que tem a ver com a recorrência a uma notícia veiculada em livro didático e datada de 1995, possivelmente uma escolha que contribui para o afastamento dos alfabetizandos adultos da experimentação de eventos de letramento socialmente efetivos. Notícias trazem consigo componentes de temporalidade aos quais precisamos endereçar nossa atenção.

A abordagem, nessa ocasião, privilegiou a oralidade, visto que o objetivo da leitura do texto foi a discussão com os alunos; entretanto as atividades de escrita propostas afastaram-se dos usos sociais da escrita, na medida em que foi solicitada a redação de um parágrafo, unidade de tratamento sistêmico.

Observamos, no Gráfico 2, que práticas oralizadas, como a contação de histórias sem compartilhamento do texto, são bastante comuns em sala de aula. Em se tratando de um processo de alfabetização e, em consequência, de apropriação e implementação das práticas de leitura e escrita, há necessidade de que o material escrito esteja presente tanto quanto possível, ou seja, que, mesmo ao se trabalhar com oralização de 
contos, o texto em questão seja compartilhado com os alunos, quer seja pelo acesso a outros textos do mesmo gênero ou pela produção de contos a partir dessas leituras e escuta, mas que as abordagens pedagógicas em sala de aula não percam o foco central de um processo de alfabetização, que é a apropriação/potencialização das práticas de leitura e escrita.

O Gráfico 2 mostra, ainda, que o trabalho com poema é bastante recorrente em sala de aula. Importa registrar que essas ações foram realizadas pela alfabetizadora I, que, como já mencionamos, parece caracterizar-se por um conhecimento ainda em construção acerca de teorizações sobre gêneros discursivos. Essas abordagens não parecem ter a esperada relação com os usos e as funções da modalidade escrita da língua a partir do desenvolvimento de atividades significativas de leitura e escrita na escola e talvez demandem uma preocupação maior com as essencialidades humanas - domínios da escrita vinculados não só ao pragmatismo cotidiano, mas a questões ontológicas mais amplas - por parte da alfabetizadora, mas com a compreensão da necessidade de progressão de dificuldade nos processos de alfabetização, ou seja, a compreensão de que, pelo fato de o poema caracterizar-se por períodos curtos, sua leitura e escrita seriam facilitadas nesse processo. Tal compreensão é evidenciada na fala da professora I: (12) Eu gosto de trabalhar com poema, música, quadrinha porque eles conseguem, sabe? Fica fácil de ler, de escrever isso, né? Os pequenos mesmo, eles adoram... (Diário de Campo - 23 de abril de 2011. Nota n. 12).

Tal compreensão remonta, em alguma medida, a critérios de ação filiados ao método sintético fônico, havendo gradação de dificuldades na exposição do aluno a leituras e escritas (MORAIS, 1996). Interessa registrar, entretanto, que não consideramos o trabalho com tal gênero equivocado; são equivocadas, em nossa compreensão, as razões que levam a esse trabalho nessa situação, ou seja, o fato de poemas terem estruturas sentenciais breves, o que, em tese, facilitaria a leitura.

Parecem existir alguns arrevezamentos, como já pontuamos, na compreensão das teorias que enfocam os usos sociais da escrita além dos apontados anteriormente e que ficam evidentes na escolha dos textos nos diferentes gêneros. O trabalho com letra de música empreendido em sala de aula e registrado em nota é ilustrativo de tais arrevezamentos:

(13) A professora entrega a música “Quem sou eu?” xerografada de material didático para que eles acompanhem a leitura realizada por alguns dos alunos que já dominam um pouco a prática. Observo que a professora não leva a música para que eles ouçam e diante dos questionamentos sobre o fato de não a conhecerem, não se propõe a trazê-la num outro momento. Os alunos juntamente com a professora discutem questões de senso-comum implicadas no texto, a partir de experiências de vida dos alunos e da docente. Por fim, é feita uma fala por uma das alunas sobre a necessidade de encaminharem uma pesquisa (parte do programa) e escolhe dois alunos para tal. Nesse momento os alunos requerem ajuda da professora para utilização do computador, ferramenta a qual não dominam, mas a professora os encaminha para o auxiliar da sala de informática, perdendo uma oportunidade de visita coletiva e mediada a essa sala. (Diário de Campo - 19 de abril de 2011 . Nota no 13).

Nessa nota, parece estar em questão a efetiva ancoragem teórica na perspectiva de usos sociais da escrita, na medida em que, embora houvesse possibilidade de um trabalho com a canção, a opção é pelo gênero letra de música, que, de todo modo, é trazida em forma de cópia não derivada do suporte em que o texto foi originalmente materializado. A letra é objeto de reflexão dissociada da música que, com ela, comporia o gênero canção, ficando tal letra restrita a um trabalho textual avulso. Parece haver, nesse ponto, arrevezamento teórico. A prática docente explicita um conhecimento ainda inicial acerca das novas teorias que preconizam o trabalho escolar em uma perspectiva dos usos sociais da língua, sugerindo não ter ainda havido apropriação teórica efetiva, o que tem se afigurado como uma característica de muitos espaços escolares 11.

\footnotetext{
${ }^{11}$ Tomazoni (2011) e Catoia Dias (2011), em estudo ainda em andamento, têm observado características semelhantes na interação com professores de Língua Portuguesa.
} 
Desdobramento desse quadro parece ser a necessidade de maior sensibilidade às vivências dos alunos. Eles demonstram interesse em iniciar uma pesquisa, algo que lhes parece relevante naquele momento, e verbalizam interesse em obter ajuda para aprender a usar o computador como ferramenta de pesquisa, mas esse uso parece não ser compreendido pela alfabetizadora como uma oportunidade educativa; não parece figurar como aula efetivamente para a professora, que parece atribuir ao caso uma dimensão apenas procedimental, o que explicaria o encaminhamento ao profissional responsável pelo setor em horário extracurricular. É importante registrar nossa compreensão de que, na ação de ambas as profissionais, há uma abertura a uma ação pedagógica diferenciada, acompanhada da necessidade de formação adequada nesse sentido (OLIVEIRA et al., 2011).

Ainda no que respeita à discussão dos eventos de letramento prevalecentes na ação escolar, o Gráfico 2 mostra o trabalho com textos característicos de atividades com crianças, o que nos remete a Souza e Mota (2007, p. 507) acerca da ação pedagógica prototípica da alfabetização de adultos "[...] quando se deslocam para a escola, [os adultos] são quase sempre infantilizados com textos de leitura e escrita que não condizem com suas experiências de vida". Tais práticas se evidenciam no trabalho com cantigas, quadrinhas etc. que são significativas na alfabetização de crianças, mas que tendem a não encontrar contraparte no universo adulto, tal qual veiculamos na nota de campo no 08.

\section{O MOVIMENTO DE RESSIGNIFICAÇÃO DAS PRÁTICAS ESCOLARIZADAS: OS GÊNEROS DISCURSIVOS E O TRABALHO COM AS NOVAS TECNOLOGIAS}

Há, porém, ações pedagógicas que se dão numa perspectiva de uso social da escrita e contam como elaboração didática (HALTÉ, 2008 [1998]) que atende aos propósitos do processo de alfabetização no universo adulto - apropriação/ potencialização das práticas de leitura e escrita em contextos de sentido -, como no trabalho com cordéis relatado na nota de campo a seguir.

(14) A professora começa sua abordagem perguntando aos alunos se eles estão assistindo à novela que tem cordel já no nome, vários alunos sabem do que se trata a novela; contam um pouco; a professora que é maranhense lança mão de alguns cordéis trazidos do Maranhão e explica como eles eram produzidos originalmente, e sobre a diferença dos de hoje e os primeiros; enquanto isso os alunos manuseiam os cordéis. Conta um pouco sobre a tradição deles e realiza a contação oral de um cordel a eles. Os alunos ouvem atentamente e continuam em poder dos cordéis passados pela professora. Os alunos ao final da leitura - na verdade, contação - fazem reflexão sobre o cordel contado e estabelecem relações com a vida deles, o que indica à professora a compreensão do texto por parte dos alunos. Por fim, ao recolher os cordéis, vários alunos pedem à professora se podem levar os materiais em questão para ler em casa, ou para o filho ler etc., ao que a professora responde afirmativamente. (Diário de Campo - 17 de junho de 2011. Nota no 14)

Essa passagem materializa uma ação docente aparentemente simples, mas que obtém resultados, em nossa avaliação, interessantes. Na ação, a professora parte de um assunto do cotidiano dos alunos, as telenovelas, com implicações nos letramentos vernaculares (HAMILTON, 2000). Do interesse dos alunos de entenderem o que é um cordel, ela aborda a questão cultural envolvida nessa prática, disponibiliza um acervo para que eles manuseiem no próprio suporte e faculta-lhes o contato com o material escrito por meio da contação a partir da percepção da hegemonia de práticas oralizadas entre os alunos, conjunto de ações que desperta, finalmente, interesse nos alunos em levar para casa os materiais escritos, convergindo assim para a busca de ressignificação das práticas de letramento desses alunos.

Pensando, por outro lado, em usos da escrita outros, que não os observados nas proposições didáticas materializados nos Gráficos 1 e 2, empreendidos pelas senhoras participantes deste estudo, o uso do computador recebe delas especial enfoque por sua restrição de uso à esfera escolar. Tal destaque se deve à importância desse instrumento explicitada na fala das próprias alunas. Embora as três refiram ter ainda dificuldade no uso dessa ferramenta, a sua utilização tem sido potencializada pela escola, que estimula tal utilização principalmente durante as pesquisas. A potencialização do uso do computador é evidenciada na fala das três participantes: 
(15) Eu tenho dificuldade, nossa!, é que no nosso tempo não tinha essas coisas, eu vim conhecer isso agora, não existia na nossa época. Na sala de aula hoje tem uma calculadora, uma coisa assim, mas antigamente não. No ano passado, o professor da pesquisa ficava comigo, ele sentava, me ajudava a mexer nas teclas ali, né? E a minha mão assim bem pesada, sem agilidade, eu tenho mão pesada pra colocar, mas a gente já tá assim aprendendo, eu penso assim tenho que comprar um notebook pra mim pra treinar. Eu gostaria de entrar numa aula de computador pra aprender. Eu nem sabia o que era Google, e o professor dizia agora vamos achar o Google, e eu dizia "professor como é que eu vou achar esse Google, nem conheço esse tal de Google" (risos). Mas eu ainda tenho dificuldade. (E., entrevista realizada em 12 de agosto de 2011 ).

(16) [Utilizo o computador] só na escola, podia usar mais, mas tudo tem seu tempo, condição de mais, no colégio, não tem pelo tempo. Só em a gente poder ir no computador já... Que nem eu sou meio atrevida, vou mexendo, peço ajuda claro, mas vou mexendo. Porque uma coisa que eu aprendi é não ter medo de nada, se eu for mexer e ele apagar, o problema é dele, tem que tocar... Eu peço ajuda, os professores sempre tão ali. Pra quantidade de alunos não tem como todos participarem horas de estudo [no computador]. (MG., entrevista realizada em 12 de agosto de 2011).

(17) Não tenho [computador em casa], só a minha filha tem. Uso computador só na escola. Ela já tentou me ensinar, é que às vezes ela me xinga um pouquinho e eu desisto (risos). Uso na escola, mas tinha que ter mais, porque às vezes, quando a gente precisa, não tem o professor que daí eles tão atendendo mais gente ou eles próprios tão fazendo algum trabalho no computador, às vezes eu quero uma ajuda de um, daí eles só dão um sinalzinho ali disso e daquilo e deixam a gente pra trás, então... Mas eu quando estou lá eu mexo, mesmo que eu saio, mexo em tudo, dá tudo errado, mas ao menos eu tô tentando mexer sabe? Mas eu acho que tinha que ter uma aula só de computador. Se eu tivesse computador em casa e soubesse usar... Que nem agora os meus trabalhos [os textos relacionados com a pesquisa] eu vou ter que pedir pra minha filha fazer porque a professora também tá tumultuada, daí eu perguntei pra ela se eu podia pedir pra ela me ajudar... E se eu soubesse mexer no computador, eu podia fazer, não precisava pedir pra ela fazer, se eu soubesse perfeitamente... Pra estudo era muito bom. (M., entrevista realizada em 07 de agosto de 2011).

Estão implicadas no discurso das três participantes demandas diferentes no uso dessa ferramenta. Essas demandas têm relação direta com o contexto extraescolar. Para E., o uso do computador demanda o auxílio imediato de uma pessoa; no caso, o professor, pela dificuldade que tem em lidar com instrumentos eletrônicos de forma geral. $\mathrm{O}$ uso ou não dessa ferramenta parece não ter utilidade prática extraescolar para ela. $\mathrm{O}$ que aprendeu já é um ganho frente à falta de acesso a tais equipamentos em sua configuração microcultural.

Já com relação à fala de MG., está subjacente uma concepção assistencialista da escolarização e dos acessos por ela facultados, especialmente quando MG. se coloca numa condição de favorecida já pelo fato de a escola lhe proporcionar o acesso a tal ferramenta, como visível em (16): "Só em a gente poder ir no computador já...”.

Interessante ainda a diferença na percepção do auxílio dos professores no uso do computador por parte de MG. e M., que explicita posturas diferentes de ambas as alunas em relação à instituição escolar. O foco assistencialista explicitado na fala de MG. é corroborado quando ela afirma que (tal qual em (16)) “[...] os professores estão sempre ali”, ao passo que M. considera a ajuda escassa quando afirma que (tal qual em (17)) “[...] quando a gente precisa não tem o professor [...]” ou que (ainda em (17)) “[...] às vezes eu quero uma ajuda de um, daí eles só dão um sinalzinho ali disso e daquilo e deixam a gente pra trás”. Considerando que ambas fazem parte da mesma turma, têm acesso relativamente semelhante, bem como auxílio equivalente, tais distinções nas falas podem ser explicadas pelas concepções diferentes acerca do processo educativo adotadas por essas duas participantes.

Tais concepções são evidenciadas em outros momentos de fala das alunas. Na fala de MG., por exemplo, há uma remissão à escola, ao processo, ao professor na perspectiva da ajuda recebida deles: (18) "[ [...] sem a escola é muito difícil, a escola é a base, os professores ajudam, estão sempre ali explicando, ajudando, eu aprendi tantas coisas..." (MG., entrevista realizada em 12 de agosto de 2011). M., por outro lado, embora reconheça os aspectos positivos do processo, remonta, em sua fala, à perspectiva crítica que adota diante da instituição escolar como um todo: 
(19) Que nem o meu objetivo de fazer concurso, assim, é pouco [conteúdo, momentos de enfoque em questões mais pontuais de ensino], eu vou ter que pegar os livros e estudar bem mais. Porque só as pesquisas não vai me adiantar no concurso se um dia eu resolver fazer. A gente aprende muito [...]. (M., entrevista realizada em 07 de agosto de 2011).

Freire (2009 [1982]), ao discutir as ressignificações necessárias ao processo educativo à luz de uma acepção mais crítica, assevera que a alfabetização de adultos não pode mais ser tratada e realizada de forma autoritária, centrada na compreensão linear e homogênea da palavra por parte dos alfabetizandos, palavra doada pelo educador aos analfabetos, imprimindo ao processo caráter assistencialista e não transformador, crítico. $\mathrm{O}$ autor define essas posturas diante do processo educacional considerando os fazeres docentes e as concepções que subjazem a eles. Entendemos, no entanto, que essas concepções acabam por ser incorporadas pelos próprios educandos no movimento de construção de identidade institucional do aluno (KLEIMAN, 2001, p. 274).

\section{CONSIDERAÇÕES FINAIS}

Entendemos, assim como propõe Street (2010), que a descrição dos eventos de letramento de determinados grupos sociais pode configurar um empreendimento desnecessário, já que não contribui efetivamente para uma ação educativa mais consequente. A compreensão das práticas, por outro lado, ainda segundo Street (2010), permite o estabelecimento de padrões nos eventos de letramento de grupos de sujeitos com compartilhamento identitário. Esse olhar sensível às práticas de letramento local, ao contrário do que acontece no modelo autônomo de letramento, é característico do modelo ideológico e pode contribuir para ações educativas mais eficientes na medida em que, ao considerar as práticas de letramento locais, a experiência escolar tende a ser mais significativa aos sujeitos. Nesse sentido, a discussão proposta aqui buscou colaborar com o campo dos estudos acerca das ações educativas escolarizadas, com vistas à alfabetização, endereçadas à parcela jovem e adulta da população.

Retomando a questão de pesquisa que norteou nosso percurso analítico - Como se caracterizam os usos sociais da escrita no espaço escolar das alfabetizandas adultas, participantes desta pesquisa, inseridas nos contornos grafocêntricos das vivências sociais em Florianópolis - SC? -, observamos que os dados apontam para usos escolares da escrita, empreendidos pelas senhoras participantes de pesquisa, que parecem se caracterizar por uma dimensão ainda bastante artificializada, restrita ao ambiente escolar, não raro com componentes de infantilização ou com aproximações demasiadamente amplas no que respeita ao senso comum, rarefazendo a escrita. Vimos, por outro lado, um movimento em busca de novas configurações, aproximações com o ideário teórico dos gêneros discursivos (BAKHTIN, 2003 [1952/53]) e um trabalho ainda inicial com as novas tecnologias. Trata-se, em nosso entendimento, de propostas didático-pedagógicas em um movimento de mudanças em relação à tradição escolarizante, mas ainda distante de configurar de fato uma ancoragem em um novo ideário.

É nosso interesse com esse trabalho - interesse esse que tem dimensão política, já que os processos educativos são fundamentalmente políticos (FREIRE, 2009 [1982]) -que as ações educativas endereçadas à parcela jovem e adulta da população ganhem contornos mais consequentes a fim de facultar as apropriações/potencializações dos usos da escrita, o que move de fato a ação docente, nesses espaços em que a escola, tal qual propõe Kleiman (2001 [1995]), é a principal agência de letramento.

\section{REFERÊNCIAS}

BAKHTIN, Mikhail. Os gêneros do discurso. In: . Estética da criação verbal. Tradução de Paulo Bezerra. 4. ed. São Paulo: Martins Fontes, 2003 [1952/53]. p. 261-306. 
BALTAR, Marcos Antonio Rocha. Mídia, escola, agentes de letramento e gêneros textuais. In: Silvana Serrani. (Org.). Letramento, discurso e trabalho docente. Vinhedo: Horizonte, 2010.

CATOIA DIAS, Sábatha. $O$ ato de ler e a sala de aula: concepções docentes acerca dos processos de ensino e aprendizagem da leitura nos anos finais do ensino fundamental na rede estadual de Florianópolis.

Dissertação (Mestrado em Linguística) - UFSC, Florianópolis, 2011.

FREIRE, Paulo. A importância do ato de ler: em três artigos que se completam. 50. ed. São Paulo: Cortez, 2009 [1982].

GERALDI, João Wanderley. A aula como acontecimento. São Carlos: Pedro \& João Editores, 2010.

HALTÉ, Jean-François. L'espace didactique et la transposition. Pratiques, Metz: Siège Social, n. 97-98, p. 171-192, juin 1998. [Trad.: O espaço didático e a transposição Fórum Linguístico, v. 5 , n. 2, p. 117-139, Florianópolis, jul./dez. 2008]. Disponível em:

http://www.periodicos.ufsc.br/index.php/forum/article/view/10800/11033.

HAMILTON, Mary. Expanding the new literacy studies: using photographs to explore literacy as social practice. In: BARTON, David; HAMILTON, Mary; IVANIC, Roz (Eds.). Situated literacies. London: Routledge, 2000.

HEATH, Shirley Brice. What no bedtime story means: narrative skills at home and school. In: DURANTI, A. (Ed.). Linguistic Anthropology: a reader. Oxford: Blackwel, 2001 [1982]. p. 318-342.

KLEIMAN, Angela Bustos. (Org.). Modelos de letramento e as práticas de alfabetização na escola. In: . Os significados do letramento: uma nova perspectiva sobre a prática da escrita. Campinas, SP:

Mercado dos Letras, 2001 [1995]. p.15-64.

O conceito de letramento e suas implicações para a alfabetização. Projeto Temático Letramento do

Professor, 2007.

Programas de educação de jovens e adultos e pesquisa acadêmica: a contribuição dos estudos do letramento. Educação e Pesquisa, São Paulo, v. 27, n.2, p. 267-281, jul/dez 2001.

MORAIS, José. A arte de ler. São Paulo: UNESP, 1996.

OLIVEIRA, Maria do Socorro; TINOCO, Glícia Azevedo; SANTOS-ARAÚJO, Ivoneide Bezerra. Projetos de letramento e formação de professores de língua materna. Natal: EDUFRN, 2011.

Santa Catarina, Secretaria de Estado da Educação, Ciência e Tecnologia. Proposta Curricular de Santa Catarina: Estudos Temáticos. Florianópolis: IOESC, 2005.

SILVA, Tomaz Tadeu da. Documentos de Identidade: uma introdução às teorias do currículo. 3. ed. Belo Horizonte: Autêntica, 2011.

SOUZA, Janine Fontes de; MOTA, Kátia Maria Santos. O silêncio é de ouro e a palavra é de prata? Considerações acerca do espaço da oralidade em educação de jovens e adultos. Revista Brasileira de Educação, v. 12, n. 36, p. 505-551, set./dez. 2007.

STREET, Brian. Os novos estudos sobre o letramento: histórico e perspectivas. In: MARINHO, Marildes; CARVALHO, Teodoro Carvalho (Orgs.). Cultura escrita e letramento. Belo Horizonte: Editora UFMG, 2010, p. 33-53.

. Abordagens alternativas ao letramento e desenvolvimento. Apresentado durante a Teleconferência Unesco Brasil sobre 'Letramento e Diversidade', outubro de 2003.

. Literacy practices and literacy myths. In: SALJO, R. (Ed.). The written world: studies in literacy thought and action. New York: Springer-Verlag, 1988.

. Literacy in theory and practice. Cambridge: CUP, 1984.

TOMAZONI, Eloara. Produção textual na disciplina de Língua Portuguesa: concepções de professores de terceiro e quarto ciclos de ensino fundamental nas escolas da rede estadual de Florianópolis, SC.

Dissertação (Mestrado em Linguística) - UFSC, Florianópolis, 2011.

VIGOTSKI, Lev Semenovich. A formação social da mente. São Paulo: Martins Fontes, 2000 [1984]. 
VÓVIO, Cláudia Lemos. Outras perspectivas sobre a alfabetização de pessoas de jovens e adultos. In: SERRANI, Silvana (Org.). Letramento, discurso e trabalho docente. Vinhedo: Editora Horizonte, 2010. p. 100115.

Recebido em 20/07/12. Aprovado em 11/09/12. 